\title{
You Better Work: 0 traballho nos Estudos de Comunicação e Música no Brasil
}

You Better Work: Work in Communication and Music Studies in Brazil

\section{Adriana da Rosa Amaral}

Professora do PPG Ciências da Comunicação da UNISINOS. Pesquisadora do CNPq. E-mail: adriamaral@unisinos.br

\section{Rafael do Nascimento Grohmann}

Professor do PPG Ciências da Comunicação da UNISINOS.

E-mail: rafaelgrohmann@unisinos.br

\section{RESUMO}

0 artigo investiga o lugar do mundo do trabalho, enquanto uma dimensão material, nos estudos de música no Brasil a partir de uma metapesquisa. 0 corpus é formado por artigos do Encontro Nacional da Compós (2015 a 2019) e do Congresso Brasileiro de Ciências da Comunicação (2012 a 2019), considerando o primeiro ano de existência dos grupos de trabalho sobre música, totalizando 178 textos. Os parâmetros de análise são: se a questão do trabalho aparece na pesquisa, ainda que não nesses termos; quais palavras são associadas ao mundo do trabalho; quais os sentidos de trabalho na área de música são empreendidos pelas investigações. Em geral, o trabalho aparece como palavra não dita e não teorizada, mas que ronda o campo a partir de sinônimos como práticas, indústria e profissionalização, principalmente em três eixos: a) indústria, negócios e mercado; b) atividades de trabalho; c) espaços e cenas onde ocorrem as atividades de trabalho.

PALAVRAS-CHAVE: Materialidades; Música; Trabalho.

Dossiê Crise, Feminismo e Comunicação - https://revistaecopos.eco.ufrj.br/

ISSN 2175-8689 - v. 23, n. 3, 2020

DOI: 10.29146/eco-pos.v23i3.27493 


\section{ABSTRACT}

The article analyzes the role of the world of work, as a material dimension, in music studies in Brazil from a meta-research. The corpus consists of articles from the Compós (2015 to 2019) and Intercom (2019) events, considering the first year of existence of these sessions, resulting in 178 texts. The dimensions of analysis are: if the question of work is present in the research, even if not in these terms; which words are associated with the world of work; which the meanings of work in the music studies. In general lines, work is a word that is not said and not theorized, but it becomes visible in synonyms such as practices, industry and professionalization, mainly in three areas: a) industry, business and the market; b) work activities; c) spaces and scenes where work activities take place.

KEYWORDS: Materialities; Music; Job.

\section{Introdução}

As condições materiais da música apresentam múltiplas dimensões, como as infraestruturas, suas condições socioculturais, os contextos econômicos e políticos, além das consequências ambientais, impactando nos modos de circulação, produção e consumo dos fazeres musicais. Esses aspectos - das materialidades midiáticas às condições materiais de produção - são inseparáveis. Isto é, as materialidades da música apresentam-se tanto enquanto concretudes dos sujeitos sociais e históricos quanto as materialidades das próprias mídias e suas interrelações mais diversas - embora esse diálogo seja, de certo modo, um ponto cego na pesquisa em comunicação.

Compreendemos essas distintas dimensões como articuladas, nos termos de Slack (1996) com inspiração de Hall (2003), como "um jogo de correspondências, não correspondências e contradições" (Slack, 1996, p. 113), com permanentes rearticulações. Deste modo, na análise de algum dos elementos, é necessário ter como pano de fundo as articulações das distintas dimensões materiais da música.

Este artigo investiga qual o lugar da dimensão do trabalho - enquanto uma das dimensões materiais - nos estudos de música no Brasil. Isto é, não é objetivo 
deste texto apreender as distintas dimensões materiais das músicas, mas tão somente compreender como o ponto de vista do trabalho se coloca como uma das dimensões materiais da música.

Trabalhar é uma atividade humana, com processos concretos e materiais algo presente desde Marx e Engels (2007) até estudos sobre trabalho em contextos digitais e no campo da comunicação como, por um lado, Huws (2014) e, por outro, Hesmondhalgh (2013), entre os mais diversos autores que tem pesquisado a plataformização do trabalho (Grohmann, 2020). Os meios e tecnologias são fruto do trabalho humano (Vieira Pinto, 2005) e as cadeias produtivas da música envolvem diferentes circuitos, cenas e fazeres. Seguindo a abordagem de Fuchs e Sandoval (2014), podemos pensar desde o marceneiro que produz uma guitarra até os engenheiros que produzem os algoritmos de plataformas de streaming de música - como um circuito do trabalho em música, nos moldes de Qiu, Crawford e Gregg (2014), também com inspiração em Hall (2003).

O exercício de metapesquisa (Mattos; Barros; Oliveira, 2018) apresentado neste artigo tem por finalidade observar regimes de visibilidade e representação dos objetos de pesquisa e das perspectivas teóricas em determinado campo de estudos, de forma a contribuir para outras possibilidades de agenda de pesquisa para a área. A hipótese desta investigação é que o mundo do trabalho aparece como pano de fundo nas pesquisas sobre música, como algo não necessariamente invisibilizado, mas ressemantizado ou não teorizado.

Constituem o corpus deste trabalho os artigos do Encontro Nacional da Compós e do Congresso Brasileiro de Ciências da Comunicação (Intercom) apresentados respectivamente nos grupos de trabalho Estudos de Som e Música entre 2015 (primeiro ano do GT) e 2019 e Comunicação, Música e Entretenimento entre 2012 (primeiro ano do GP) e 2019. Respectivamente são 50 e 128 artigos analisados, totalizando 178 textos.

Os parâmetros de análise são: a) se a questão do trabalho aparece na pesquisa, ainda que não nesses termos; b) quais palavras são associadas ao mundo

Dossiê Crise, Feminismo e Comunicação - https://revistaecopos.eco.ufri.br/

ISSN $2175-8689$ - v. 23, n. 3, 2020

DOI: 10.29146/eco-pos.v23i3.27493 
do trabalho; c) quais os sentidos de trabalho na área de música são empreendidos pelas investigações. Desta forma, investigamos como a noção de trabalho circula com diferentes sentidos e campos semânticos pela literatura sobre música no Brasil. Não estão no escopo desta metapesquisa quais os referenciais teóricos mais acionados ou os métodos mais utilizados, pois o foco é organizar como aparece a questão do trabalho - com seus regimes de visibilidade - nos estudos de música no país de forma a evidenciar potencialidades dessa discussão para a área.

\subsection{Trabalho no GT Estudos de Som e Música da Compós}

Segundo o site da Compós, o GT Estudos de Som e Música foi criado em 26/06/20141. Sua atual ementa caracteriza os estudos apresentados no grupo:

Reúne trabalhos de cunho teórico-metodológico e/ou empírico que analisam aspectos estéticos, tecnológicos, socioeconômicos e políticos associados ao universo das sonoridades, contemplando as dinâmicas de produção, circulação e consumo musical nos ambientes midiáticos. As questões privilegiadas gravitam em torno dos seguintes eixos: a) disputas de valor e rotulações em torno de gêneros, cenas, redes e circuitos musicais; b) práticas e trânsitos de coletivos e fandoms musicais em suas dimensões locais, nacionais ou globais; c) a mediação dos formatos, suportes e meios nas experiências sonoras; d) o papel do som na cultura audiovisual; e) som, música e ativismo: articulações e tensões na construção de identidades; f) estética e linguagem da canção; g) som, música, corpo, afeto e audibilidades; h) paisagens sonoras, mídias, territorialidades e espaços urbanos; i) Sound Design e ruídos; j) estudos de rádio, de televisão, de cinema, de videogames, de plataformas digitais articulados ao mercado fonográfico; $\mathrm{k}$ ) economia da música no contexto das indústrias criativas e da cultura digital; l) mídia, música e moda; m) arte e experimentações sonoras; $n$ ) som e música enquanto expressões do universo do lúdico e/ou do entretenimento; o) relações entre música, idolatria (culto às celebridades) e cultura pop.

A palavra "trabalho" não aparece em nenhum momento, mas há alguns indícios de onde ela pode estar semanticamente presente, como em "práticas" e “economia da música no contexto das indústrias criativas e da cultura digital”.

\footnotetext{
${ }^{1}$ Disponível em $<$ http://www.compos.org.br/ler_gts.php?idGt=MzQ=>. Acesso em 10/04/2020.

Dossiê Crise, Feminismo e Comunicação - https://revistaecopos.eco.ufrj.br/

ISSN 2175-8689 - v. 23, n. 3, 2020

DOI: 10.29146/eco-pos.v23i3.27493
} 
Dos 50 artigos apresentados no GT Estudos de Som e Música da Compós, apenas 17 tratam, de alguma maneira, do mundo do trabalho, sendo 5 em 2015, 5 em 2016, 4 em 2017, 3 em 2018 e 1 em 2019, de um total de 10 textos por ano. A partir do corpus, podemos apreender os sentidos de trabalho atravessados por três principais dimensões: a) economia ou indústria da música, com um olhar "macro" para o mercado; b) as atividades de trabalho dos músicos, como sinônimo de práticas, formas de produção e sobrevivência; c) os espaços onde ocorrem as atividades de trabalho, em alguns momentos entendidos como contextuais em relação ao trabalho (como aspecto de uma cena musical, por exemplo) e, em outros, como parte do próprio mundo do trabalho, ao tratar de coletivos de festas, por exemplo.

Do primeiro grupo fazem parte os textos de Kischinhevsky (2015), Vicente (2016), Kischinhevsky e De Marchi (2016), De Marchi (2017), Vinícius Pereira (2018) e De Marchi e Santos (2019), com perspectivas relacionadas à indústria, ao mercado e à economia. Embora os artigos não mencionem a palavra "trabalho" em nenhum momento, consideramos que, ao abordar as cadeias produtivas de produção, tal qual a posição adotada por Fuchs e Sandoval (2014), trata-se de um olhar possível para o mundo do trabalho. Algumas das expressões utilizadas são "inovações no modelo de negócio da indústria da música", "reconfiguração dos mercados de mídia", "major e indies na era digital", "produção de valor", "mercado digital de música", "mercado sonoro" e "viés econômico da indústria fonográfica".

Neste mesmo eixo, há distintas abordagens conceituais, como a "lógica social do derivativo" (De Marchi, 2017) e as "modulações da escuta e cultura aural" (Pereira, 2018). Contudo, consideramos que eles se agrupam em um olhar mais amplo em relação ao mundo do trabalho (mesmo nunca nomeado enquanto tal), sem necessariamente um diálogo com a economia política da comunicação, pensando em questões como modelos de negócio e as reconfigurações do mercado, com os diferentes players envolvidos, como serviços de streaming ou plataformas de distribuição de música e gravadoras.

\section{Dossiê Crise, Feminismo e Comunicação - https://revistaecopos.eco.ufrj.br/}

ISSN 2175-8689 - v. 23, n. 3, 2020

DOI: 10.29146/eco-pos.v23i3.27493 
Entre esse eixo que acabamos de apresentar e o próximo, mais vinculado às atividades de trabalho propriamente, podemos posicionar dois textos: Amaral, Monteiro e Soares (2015) e Gomes (2015). De um lado, esses artigos apresentam um olhar em relação à indústria musical (gravadoras, obras), e, por outro, abordam também a criatividade e a performance dos músicos. Isso ocorre em Amaral, Monteiro e Soares (2015) a partir dos "críticos-fãs de música", considerando que é a partir da "performance de músico, de fãs e de críticos como disposições e lugares de fala que operacionalizam gostos e afetos nas disputas genéricas" (Amaral; Monteiro; Soares, 2015, p. 13). Já em Gomes (2015), essas articulações aparecem a partir do diálogo com Raymond Williams no plano teórico. A autora considera que "inovações na cultura nunca são apenas da ordem da criatividade do artista, mas têm lugar nas articulações entre música e tecnocultura" (Gomes, 2015, p. 13).

O segundo conjunto de artigos, efetivamente, aborda as atividades de trabalho na área de música - mesmo que essas não estejam em primeiro plano com foco nas pessoas e coletivos que praticam/produzem música, com protagonismo da pesquisa de Simone Luci Pereira (autora ou coautora de 4 dos 5 artigos). São eles: Pereira e Borelli (2015), Pereira e Pinto (2016), Soares e Pereira (2017), Gelain et al. (2018) e Simone Pereira (2018). Algumas das expressões que aparecem nos textos são: "práticas musicais-midiáticas", "organização profissional", "formas alternativas e não-oficiais de produção", "trabalho em rede", "formas colaborativas e autogestionárias", "do it yourself".

Uma tônica é como os músicos e suas redes fazem a gestão da sua própria sobrevivência, seja em relação à carreira ou em eventos, festas e festivais. Os cenários descritos aproximam o trabalho do músico daquilo que se chama na sociologia do trabalho de "viração" (Rizek, 2006), enfatizando formas alternativas e colaborativas de produção, próximo ao que Fígaro e Nonato (2017) denominam como "arranjos alternativos" na compreensão do trabalho de jornalistas.

Embora haja certa positivação de imperativos de uma racionalidade empreendedora (nos termos de Dardot e Laval, 2016) na fala de alguns

\section{Dossiê Crise, Feminismo e Comunicação - https://revistaecopos.eco.ufri.br/}

ISSN 2175-8689 - v. 23, n. 3, 2020

DOI: 10.29146/eco-pos.v23i3.27493 
entrevistados (Pereira; Borelli, 2015), as pesquisas empíricas revelam uma preponderância de ações colaborativas, autogestionárias e em rede, isto é, um fazer coletivo e cooperativo entre os sujeitos que produzem e fazem circular a música, inclusive com formação de associações. Simone Pereira (2018), ao investigar os coletivos de música eletrônica de pista em São Paulo, chega a nomear suas práticas como "formas colaborativas e autogestionárias de organização e produção das festas e dos eventos extrafestas (festivais, cursos, encontros, etc.)" (Pereira, 2018, p. 1). Trata-se da colaboração como enfrentamento às difíceis situações de trabalho, a exemplo do que mostra a pesquisa de Sandoval (2017). Isso não significa que essas práticas sejam livres de contradições. Entre a total adesão à uma racionalidade empreendedora e a completa resistência aos modelos produtivos vigentes, há uma miríade de possibilidades, discursos e organizações. Isso, de alguma forma, é refletido pelas pesquisas analisadas.

De alguma forma, essas investigações são uma amostra das mudanças no mundo do trabalho. No texto de Pereira e Pinto (2016) sobre o trabalho dos compositores, por exemplo, observamos a multifunção/multitarefa e a polivalência como atributos em um universo expandido de atuação "para além da música do cinema e [que] também compõem para o videogame, a publicidade, a televisão e outros conteúdos" (Pereira; Pinto, 2016, p. 3), trabalhando em conectividade constante (Wajcman, 2017). Esse alargamento revela a multiplicidade de atividades de trabalho possíveis na área de música, desde as funções até os seus lugares ou produtos, como eventos, cursos e festivais. Isso ocorre em meio a indistinções entre lazer e trabalho e também "indistinção ou sobreposição, dos lugares do profissional e do amador na música" (Pereira; Pinto, 2016, p. 4).

Esse processo está em linha com estudos sobre trabalho digital, como Van Doorn (2017), Abílio (2019) e Huws (2014) que analisam a amadorização do trabalho como um processo intensificado pela plataformização ou uberização do trabalho. Isso se relaciona também à conectividade constante como um elemento do trabalho 24 horas por dia, com eliminação do tempo morto e borrar - cada vez

Dossiê Crise, Feminismo e Comunicação - https://revistaecopos.eco.ufrj.br/

ISSN $2175-8689$ - v. 23, n. 3, 2020

DOI: 10.29146/eco-pos.v23i3.27493 
maior - de fronteiras entre tempo de trabalho e de não trabalho (lazer), com a vida sendo tomada por um tempo considerado "produtivo" para o capitalismo.

Em Gelain et al. (2017), há a única pesquisa do corpus que, de alguma forma, relaciona o mundo do trabalho e gênero a partir de uma "rede musical didática, formada por musicistas e feministas" (Gelain et al., 2017, p. 3), evidenciando que "escritores, técnicos, criadores, músicos populares, produtores e engenheiros são majoritariamente do sexo masculino" (GELAIN et al., 2017, p. 5), com a apropriação masculina dos meios de produção. As práticas das mulheres que organizam o Girls Rock Camp Porto Alegre utilizam-se da lógica do it yourself, assim como as mulheres trabalhadoras da cultura digital no Japão investigadas por Gabriella Lukács (2020), envolvendo a visibilidade de suas produções por meio das tecnologias digitais. Contudo, Lukács (2020) alerta para o fato de que coletivos e carreiras baseados no do it yourself apresentam tempos de vida de curto prazo no capitalismo contemporâneo.

Em suma, com relação aos sentidos de trabalho expressos por esse conjunto de artigos, podemos afirmar que: a) há uma inclinação para a positivação das práticas alternativas, próximo ao que Brophy e Cohen (2015) chamam de "práticas autônomas de comunicação", envolvendo, inclusive, os sentidos políticos das práticas de trabalho, articulados a questões de gênero e raça; b) por outro lado, as práticas instáveis de sujeitos e coletivos não são lidas em termos de precariedade ou precarização de suas atividades de trabalho; c) há uma invisibilidade do termo "trabalho", embora a descrição dos fenômenos investigados seja, de alguma maneira, própria do mundo do trabalho.

Embora todos esses textos analisem as práticas musicais em relação com contextos urbanos e de cidade ("usos do espaço e dos corpos na cidade", como em Pereira, 2018), há ainda certo protagonismo na descrição e interpretação das suas atividades de trabalho. No terceiro conjunto de artigos que aqui analisamos, a centralidade é mesmo dos espaços onde ocorrem as atividades de trabalho, entendidas apenas como um aspecto coadjuvante (quase invisível) da cena 
musical. Fazem parte desse grupo os seguintes textos: Janotti Junior e Almeida (2015), Herschmann e Oliveira (2016), Bezerra (2016), Alonso e Reichelt (2016), Almeida e Janotti Junior (2017) e Reia (2018).

0 trabalho, enquanto entidade semi-invisível desses trabalhos, pode ser pinçado a partir de noções como "cena musical” (Bezerra; Alonso; Reichelt, 2016), "dinâmicas espaciais e temporais da música" (Almeida; Janotti Junior, 2017) e "espacialidades da música" (Janotti Junior; Almeida, 2015) - que podemos analisar como aspectos materiais cristalizados do trabalho na área de música. Elementos como palco, instrumentos, estruturas e som - enquanto materialidades midiáticas - podem ser compreendidos também como as materialidades do trabalho inscritas nas mídias/nos espaços. Isto é, a inscrição da música em espaços é, ao mesmo tempo, mídia e resultado/concretização de trabalho. Isso mostra, de alguma forma, as articulações entre distintas dimensões das materialidades da música - enquanto trabalho e materialidade midiática.

A música ao vivo aparece em três dos cinco artigos, a saber Janotti Junior e Almeida (2015), Bezerra, Alonso e Reichelt (2016) e Almeida e Janotti (2017). Destacamos a análise do Edifício Pernambuco, em Janotti Junior e Almeida (2015), como um locus das espacialidades da música ao vivo e também do mundo do trabalho: "muitos desses músicos têm atividades de trabalho no próprio Edifício Pernambuco" (Janotti Junior; Almeida, 2015, p. 14). Ali há produtoras de vídeo e circulam publicações sobre música, com diferentes coletivos. O Edifício, então, é observado como um espaço de coworking, a partir do qual a cena musical ocorre.

À semelhança de artigos de Simone Luci Pereira (2018), há relações entre espaços e produção. A diferença está no tom: a produção e o trabalho são quase imperceptíveis nas pesquisas desse terceiro conjunto de textos. Em Herschmann e Oliveira (2016), por exemplo, a centralidade está na proposta do Baile Black Bom. 0 mundo do trabalho pode ser observado na compreensão do espaço como algo que une baile, oficinas de arte e cultura afro e afroempreendedorismo - o que não é explorado para além da descrição de sua existência.

\section{Dossiê Crise, Feminismo e Comunicação - https://revistaecopos.eco.ufrj.br/}

ISSN 2175-8689 - v. 23, n. 3, 2020

DOI: 10.29146/eco-pos.v23i3.27493 
Já o texto de Reia (2018) articula a rua como espaço musical e o trabalho de artistas de rua. Para a autora, "a música de rua, para que o artista possa 'formar roda' e 'passar o chapéu', precisa levar em conta o espaço no qual ela acontece" (Reia, 2018, p. 3). Há, nessa pesquisa, ainda que de forma tímida, uma articulação mais substancial que não considera apenas o espaço, mas a realidade dos músicos, inclusive levando em conta aspectos de precariedade e estigmas - não tão comuns no segundo conjunto de textos analisados, por exemplo. Os artistas de rua investigados em Reia (2018) "acumulam uma longa história de informalidade, marginalização e perseguição por parte do poder público, enfrentando também estigmatização por diversos grupos da sociedade" (Reia, 2018, p. 2).

A partir das análises, consideramos que há articulações e pontos de contato entre os três conjuntos de artigos, pois são dimensões das próprias materialidades do trabalho na área de música: 1) indústria, mercado e economia; 2) atividades de trabalho; 3) espaços de trabalho e espaços urbanos. Em seguida, analisamos os artigos publicados no Congresso Brasileiro de Ciências da Comunicação Intercom.

\subsection{Trabalho no GP Comunicação, Música e Entretenimento da Intercom}

O Grupo de Pesquisa Comunicação, Música e Entretenimento da Intercom localiza-se dentro da Divisão Temática 6 - Interfaces Comunicacionais tendo sido aprovado em 2011. Sua atual ementa descreve as pesquisas realizadas no âmbito do GP da seguinte forma:

Reunir estudos que atuem na interface entre comunicação, música e entretenimento e que privilegiem: a) o compromisso em construir novos instrumentos de análise que possam dar conta do conjunto de temáticas e desafios abordados em geral pelos pesquisadores (ou seja, que priorizem o compromisso com a renovação do arcabouço teórico-metodológico); b) em suas análises tanto os próprios produtos midiáticos, bem como suas instâncias de produção, circulação e consumo seja nos circuitos, cenas ou cadeias produtivas; c) as tensões e articulações entre produtos, rotulações,

Dossiê Crise, Feminismo e Comunicação - https://revistaecopos.eco.ufrj.br/

ISSN 2175-8689 - v. 23, n. 3, 2020

DOI: 10.29146/eco-pos.v23i3.27493 
gêneros e formatos, formas de expressão e recepção, estilos e tendências que se fazem presentes no universo da música e, de modo geral, do entretenimento; d) a avaliação da relevância da audibilidade (condições de emissão e de escuta) e da portabilidade para a conformação da experiência sonora e do entretenimento; e) os aspectos sociopolíticos significativos presentes no universo da música e do entretenimento; f) a problematização da relação entre as novas tecnologias e o condicionamento dos ambientes sonoros e espetaculares; g) em suas análises as articulações e conflitos entre música/entretenimento, identidade e espacialidade; h) a análise das relações entre corpo, moda, música e entretenimento; i) a elaboração de balanços da crescente importância da economia da música e do entretenimento; i) as conformações das cenas culturais em seus aspectos estéticos e mercadológicos 2 .

Assim como no grupo da Compós, aqui a palavra trabalho não é mencionada, mas pode ser pinçada a partir de expressões como "instâncias de produção", “cadeias produtivas", “economia da música e do entretenimento", "conformações das cenas culturais em seus aspectos [...] mercadológicos".

Devido às características mais inclusivas do Congresso da Intercom, os textos analisados aqui foram tratados por uma abordagem mais quantitativa a fim de um mapeamento. Para tanto, observamos a partir de nossa hipótese inicial que as três dimensões acima citadas se mantiveram, porém acrescidas de outras subcategorias que foram ampliadas.

Dos 266 artigos disponibilizados, foi efetuada a análise de 128 trabalhos apresentados ao longo de oito anos de funcionamento do GP Comunicação, Música e Entretenimento da Intercom ${ }^{3}$. Os textos foram escritos por doutores, doutorandos, mestres, mestrandos e especialistas. Apesar de não haver menção direta ao tema na maior parte dos trabalhos, a partir da análise quantitativa vemos que aproximadamente 48,1\% dos trabalhos apresentados no GP relacionam-se de

Disponível em: http://www.portalintercom.org.br/eventos1/gps1/gp-comunicacao-musica-eentretenimento . Acesso em 13/04/2020.

${ }^{3}$ Apesar da disponibilização online de todos os anais dos eventos, centralizados a partir de um link no Portal da Intercom (http://portalintercom.org.br/eventos1/congresso-nacional/apresentacao5), salientamos a dificuldade da contagem de seleção e contagem de artigos, pois em muitos anos do evento não havia uma indicação do número de trabalhos apresentados na página, o que nos fez contar manualmente os textos.

Dossiê Crise, Feminismo e Comunicação - https://revistaecopos.eco.ufrj.br/

ISSN 2175-8689 - v. 23, n. 3, 2020

DOI: 10.29146/eco-pos.v23i3.27493 


\section{PERSPECTIVA}

alguma forma às materialidades e discutem, mesmo que de forma tímida, formas e relações entre comunicação, música e mundo do trabalho.

Uma observação inicial importante é que apesar do GP ter o Entretenimento em seu título ${ }^{4}$ o grande foco é na relação entre comunicação e música em suas mais amplas formas e mídias. Localizamos alguns trabalhos sobre Histórias em Quadrinhos - que foram diretamente excluídos da amostra - e alguns sobre Dança (alguns ficaram e outros foram excluídos a partir de dois critérios: a relação com as temáticas sonoras e musicais e a relação com a questão do trabalho). Um outro ponto a ser destacado é que a maior parte dos trabalhos relacionados à música e estética foram descartados da amostra por não abordarem ou tematizarem nenhuma questão relacionada a formas de trabalho na área da música.

\begin{tabular}{|l|l|l|}
\hline ANO DO GP & $\begin{array}{l}\text { TRABALHOS } \\
\text { APRESENTADOS }\end{array}$ & $\begin{array}{l}\text { TRABALHOS } \\
\text { SELECIONADOS }\end{array}$ \\
\hline $\mathbf{2 0 1 2}$ & 29 & 15 \\
\hline $\mathbf{2 0 1 3}$ & 17 & 11 \\
\hline $\mathbf{2 0 1 4}$ & 29 & 17 \\
\hline $\mathbf{2 0 1 5}$ & 43 & 15 \\
\hline $\mathbf{2 0 1 6}$ & 40 & 19 \\
\hline $\mathbf{2 0 1 7}$ & 33 & 17 \\
\hline $\mathbf{2 0 1 8}$ & 40 & 17 \\
\hline $\mathbf{2 0 1 9}$ & 35 & 17 \\
\hline Total & 266 & 128 \\
\hline
\end{tabular}

Tabela 1: seleção da amostra

Num segundo momento categorizamos os trabalhos a partir das três dimensões observadas para termos uma ideia de quais tendências de articulação apareciam de forma mais proeminente no GP, a saber: a) economia ou indústria da música; b) atividades de trabalho de músicos; c) espaços onde ocorrem as atividades de trabalho.

${ }^{4}$ Além disso, observamos que em vários anos o nome do GP encontra-se escrito de forma errada nos links disponíveis, como Comunicação, Música e Entreterimento com R.

Dossiê Crise, Feminismo e Comunicação - https://revistaecopos.eco.ufrj.br/

ISSN 2175-8689 - v. 23, n. 3, 2020

DOI: 10.29146/eco-pos.v23i3.27493 
Observamos também que alguns trabalhos poderiam ser articulados a partir de mais de uma dessas dimensões, ao que denominamos Entre Eixos. A quantidade de trabalhos analisada por categoria em cada ano encontra-se abaixo.

\begin{tabular}{|l|l|l|l|l|l|}
\hline ANO DO GP & A & B & C & ENTRE EIXOS & SELECIONADOS \\
\hline $\mathbf{2 0 1 2}$ & 1 & 4 & 5 & 5 & 15 \\
\hline $\mathbf{2 0 1 3}$ & 4 & 4 & 2 & 1 & 11 \\
\hline $\mathbf{2 0 1 4}$ & 5 & 7 & 3 & 2 & 17 \\
\hline $\mathbf{2 0 1 5}$ & 3 & 4 & 6 & 2 & 15 \\
\hline $\mathbf{2 0 1 6}$ & 8 & 4 & 4 & 3 & 19 \\
\hline $\mathbf{2 0 1 7}$ & 4 & 6 & 4 & 3 & 17 \\
\hline $\mathbf{2 0 1 8}$ & 9 & 4 & 1 & 3 & 17 \\
\hline $\mathbf{2 0 1 9}$ & 7 & 4 & 2 & 4 & 17 \\
\hline Total & 41 & 37 & 27 & 23 & 128 \\
\hline
\end{tabular}

Tabela 2: categorização a partir das dimensões observadas

A partir dessa primeira mirada nos artigos, percebemos que os estudos de comunicação e música em sua maioria discutem as questões sobre o trabalho a partir de uma categoria mais ampla, relacionada ao mercado e à indústria; em segundo lugar nos trabalhos relacionados às rotinas produtivas dos músicos e suas atividades e por fim no âmbito das cenas e dos espaços urbanos. Também é possível observar que a variedade entre as categorias por ano se mantém relativamente estável. Já os artigos que discutem, ainda que brevemente, o tema do trabalho em si, possuem aderência em dois eixos, porém são em menor número. Talvez isso aconteça pela dificuldade que o formato artigo apresenta para a discussão de dados de temas amplos - delimitação de número de caracteres, ou pelo próprio endereçamento teórico-metodológico de cada uma das áreas.

Para tanto, também interpretamos as articulações entre as categorias, resultando na seguinte tabela.

\begin{tabular}{|l|l|l|l|l|}
\hline ANO DO GP & ENTRE EIXOS & A-B & A-C & B-C \\
\hline $\mathbf{2 0 1 2}$ & 5 & 0 & 2 & 3 \\
\hline $\mathbf{2 0 1 3}$ & 1 & 0 & 1 & 0 \\
\hline $\mathbf{2 0 1 4}$ & 2 & 0 & 2 & 0 \\
\hline $\mathbf{2 0 1 5}$ & 2 & 1 & 1 & 0 \\
\hline $\mathbf{2 0 1 6}$ & 3 & 3 & 0 & 0 \\
\hline
\end{tabular}

Dossiê Crise, Feminismo e Comunicação - https://revistaecopos.eco.ufrj.br/

ISSN 2175-8689 - v. 23, n. 3, 2020

DOI: 10.29146/eco-pos.v23i3.27493 


\begin{tabular}{|l|l|l|l|l|}
\hline $\mathbf{2 0 1 7}$ & 3 & 3 & 0 & 0 \\
\hline $\mathbf{2 0 1 8}$ & 3 & 0 & 2 & 1 \\
\hline $\mathbf{2 0 1 9}$ & 4 & 1 & 3 & 0 \\
\hline TOTAL & 23 & 8 & 11 & 4 \\
\hline
\end{tabular}

Tabela 3: artigos categorizados em mais de um eixo

É importante indicar que tradicionalmente os estudos sobre cenas musicais, cidades e espaços urbanos constitui uma das temáticas centrais nas pesquisas brasileiras (Sá \& Janotti Jr, 2013) e com maior número de trabalhos nos eventos. Mesmo assim, parece ainda discutir pouco a questão das práticas de trabalho em si. Por outro lado, somando o número de trabalhos que tratam de cenas musicais articulado com questões relativas aos músicos e ao mercado e indústria (Tabela 3) entendemos que para o avanço desse debate faz-se necessária a problematização sobre as práticas de trabalho.

Um tema recorrente observado nos artigos do GP Comunicação, Música e Entretenimento diz respeito ao consumo musical, seja a partir das práticas, da fruição estética e das materialidades da cultura digital e da mediação das tecnologias de comunicação; seja nos estudos sobre fãs de determinados gêneros musicais ou artistas e suas formas de engajamento. Festivais e shows também fazem parte desse circuito de análises e formas de consumo e experiências das audiências em sua relação entre mídia e música.

Também observamos que a relação com o audiovisual, sobretudo o videoclipe, aparece bastante, bem como a questão da performance, ora mais discutida como trabalho da persona do artista, ora a partir de álbuns, shows e entrevistas e até mesmo em sua relação com as mídias sociais e a internet.

Outras temáticas que possuem angulações interessantes com o mundo do trabalho e que aparecem nos artigos do GP é a relação com o jornalismo cultural/musical e o papel dos críticos e da própria crítica; a relação música pop educomunicação a partir do papel dos professores e o endereçamento de políticas públicas relacionadas à indústria fonográfica e à profissionalização dos músicos em diferentes cenas.

\section{Dossiê Crise, Feminismo e Comunicação - https://revistaecopos.eco.ufrj.br/}

ISSN 2175-8689 - v. 23, n. 3, 2020

DOI: 10.29146/eco-pos.v23i3.27493 


\section{Considerações Finais}

0 mundo do trabalho é uma das maneiras de apreender as dimensões materiais da música, considerando desde as condições concretas e materiais das atividades de trabalho até as materialidades midiáticas - ao mesmo tempo expressão do trabalho humano e com produção de sentido a partir dos próprios meios - a partir de uma visão para as cadeias globais de produção, circulação e consumo da música, entendidas a partir de suas articulações.

Nos estudos de música no Brasil, conforme analisado em artigos de congressos da área, o trabalho aparece como palavra não dita e não teorizada, mas que ronda o campo a partir de sinônimos, tais como práticas, indústria, profissionalização, entre outros. Os sentidos do trabalho circulam, pois, em segundo plano, como coadjuvantes, principalmente em três eixos: a) indústria, negócios e mercado; b) atividades de trabalho, práticas e redes de colaboração; c) trabalho como pano de fundo para compreensão de espaços e cenas. Isso não significa a completa invisibilidade, mas nomear e organizar esses eixos a partir do mundo do trabalho pode auxiliar no desenvolvimento da área no país. Isto é, o mundo do trabalho é tematizado como uma dimensão material da música nos estudos brasileiros: apenas não deixa ser visto. Nesse sentido que fazemos uma provocação para a área a partir da cantora Britney Spears: you better work.

Nesse esforço de organização e visibilização do mundo do trabalho como dimensão material da música, uma das possibilidades, a nosso ver, deve-se às articulações entre os diferentes "momentos" - na apreensão marxiana (Marx, 2011) - do circuito da música e seus modos de produção, circulação e consumo, posicionando o mundo do trabalho como uma das dimensões materiais da música. Essa visibilidade pode ajudar a evidenciar o que há de específico nas práticas musicais em relação ao processo de plataformização do trabalho - por exemplo, as 
lives - e o que acompanharia tendências de outros setores e já preconizadas por pesquisas sobre trabalho digital.

\section{Referências bibliográficas}

ABILIO, Ludmila Costhek. Uberização: do empreendedorismo ao autogerenciamento subordinado. Psicoperspectivas, v. 18, n. 3, p. 1-11, 2019. Disponível em: <https://tinyurl.com/UberizacaoPsicoperspectivas19>. Acesso em: 15 de mar. de 2020.

ALMEIDA, Laís; JANOTTI JUNIOR, Jeder. Dinâmicas espaciais e temporais da música ao vivo no Centro de Recife. Trabalho apresentado no GT Estudos de Som e Música do XXVI Encontro Anual da Compós. São Paulo: Cásper Líbero, 2017. Disponível em: <http://compos.org.br/anais_texto_por_gt.php?idEncontro=MjY=>. Acesso em 15 de mar. de 2020.

AMARAL, A.; MONTEIRO, C.; SOARES, T. "Whats's Going On" é o "Sgt Peppers" da soul music. Trabalho apresentado no GT Estudos de Som e Música do XXIV Encontro Anual da Compós. Brasília: UnB, 2015. Disponível em: <http://www.compos.org.br/biblioteca/composadrithikoscamis_2854.pdf >. Acesso em 15 de mar. de 2020.

BEZERRA, Amilcar; ALONSO, Gustavo; REICHELT, Henrique. Sertanejo, manguebeat e Tchê-music: da pertinência (ou não) do conceito de cena musical para gêneros periféricos. Trabalho apresentado no GT Estudos de Som e Música do XXV Encontro Anual da Compós. Goiânia:UFG, 2016. Disponível em:

$<$ https://tinyurl.com/Compos-SertanejoMangueb-Tche>. Acesso em 15 de mar. de 2020.

BROPHY, Enda; COHEN, Nicole S.; DE PEUTER, Greig. Labour Messaging: practices of autonomous communication. In: MAXWELL, Richard (org.). The Routledge Companion to Labor and Media. New York: Routledge, 2015. p. 315-326.

CUBITT, Sean. Finite Media: Environmental Implications of Digital Technologies. Durham: Duke University Press, 2017.

Dossiê Crise, Feminismo e Comunicação - https://revistaecopos.eco.ufrj.br/

ISSN 2175-8689 - v. 23, n. 3, 2020

DOI: 10.29146/eco-pos.v23i3.27493 
DARDOT, Pierre; LAVAL, Christian. A Nova Razão do Mundo. São Paulo: Boitempo, 2016.

DE MARCHI, Leonardo. Como monetizar seu vídeo no Youtube? Análise da produção de valor para conteúdos digitais através da lógica social do derivativo. Trabalho apresentado no GT Estudos de Som e Música do XXVI Encontro Anual da Compós. São Paulo: Cásper Líbero, 2017. Disponível em:<https://tinyurl.com/Compos-YoutubeMonetarizar>. Acesso em 15 de mar. de 2020.

DEMARCO, Matheus; SANTOS, Giordanna. Políticas de recomendação de conteúdo: as tensões entre o viés econômico da indústria fonográfica e as premissas de sociabilidade de plataformas de distribuição de música online. Trabalho apresentado no GT Estudos de Som e Música do XXVIII Encontro Anual da Compós. Porto Alegre: PUC-RS, 2018. Disponível em:

$<$ https://tinyurl.com/ComposRECConteudo>. Acesso em 15 de mar. de 2020.

FÍGARO, Roseli; NONATO, Cláudia. Novos "Arranjos Econômicos" Alternativos para a Produção Jornalística. Contemporânea, v. 15, n. 1, p. 47-63, 2017.

FUCHS, Christian; SANDOVAL, Marisol. Digital workers of the world unite! A framework to critically theorising and analysing digital labour. TripleC, v. 22, n. 2, p. 486-563, 2014. Disponível em: <https://www.triplec.at/index.php/tripleC/article/view/549>. Acesso em: 10 de mar. de 2020.

GELAIN, Gabriela et al. Tecnologias musicais, materialidades artísticas e ativismo feminino: o caso Girls Rock Camp Porto Alegre. Trabalho apresentado no GT Estudos de Som e Música do XXVI Encontro Anual da Compós. São Paulo: Cásper Líbero, 2017. Disponível em: <https://tinyurl.com/ComposMAT-Feminismo>. Acesso em: 15 de mar. de 2020.

GOMES, Itânia. Articulações entre música e tecnocultura no Led Zeppelin. Trabalho apresentado no GT Estudos de Som e Música do XXIV Encontro Anual da Compós. Brasília: UnB, 2015. Disponível em: <https://tinyurl.com/ComposLedZeppelinUNB15>. Acesso em: 15 de mar. de 2020. 
GROHMANN, Rafael. Plataformização do trabalho: entre dataficação, financeirização e racionalidade neoliberal. EPTIC, v. 22, n. 1, p. 106-122, 2020.

HALL, Stuart. Da Diáspora. Belo Horizonte: Ed. UFMG, 2003.

HERSCHMANN, Micael; OLIVEIRA, Luciana Xavier. Comunicação, Música e Estilos de Vida Agenciados no Baile Black Bom. Trabalho apresentado no GT Estudos de Som e Música do XXV Encontro Anual da Compós. Goiânia: UFG, 2016. Disponível em:

<http://www.compos.org.br/biblioteca/artigom\%C3\%BAsicanobaileblackbomvers\%C3\%A3ocompleta_3379.pdf>. Acesso em: 10 de mar. de 2020.

HESMONDHALGH, David. The Cultural Industries. London: Sage, 2013.

HUWS, Ursula. Labor in the Global Digital Economy. New York: Monthly Review Press, 2014.

JANOTTI JUNIOR, Jeder.; SÁ, Simone P. Revisitando a noção de gênero musical em tempos de cultura musical digital. Trabalho apresentado no GT Estudos de Som e Música do XXVII Encontro Anual da Compós. Anais do XXVII Encontro Anual da Compós. Belo Horizonte: PUC-MG, 2018. Disponível em: <https://tinyurl.com/Compos18ArqGTs>. Acesso em: 12 de fev. de 2020.

JANOTTI JUNIOR, Jeder; ALMEIDA, Lais. Edifício Pernambuco: espacialidades da música ao vivo no projeto ExcentriCidades através de uma constelação de conceitos. Trabalho apresentado no GT Estudos de Som e Música do XXIV Encontro Anual da Compós. Brasília: UnB, 2015. Disponível em <http://www.compos.org.br/biblioteca/arquivocompleto_2859.pdf> . Acesso em: 10 de abr. de 2020

KISCHINHEVSKY, Marcelo. Música infinita: serviços de streaming como espaços híbridos de comunicação e consumo musical. Trabalho apresentado no GT Estudos de Som e Música do XXIV Encontro Anual da Compós. Brasília: UnB, 2015. Disponível

Dossiê Crise, Feminismo e Comunicação - https://revistaecopos.eco.ufrj.br/

ISSN 2175-8689 - v. 23, n. 3, 2020

DOI: 10.29146/eco-pos.v23i3.27493 
em: <http://compos.org.br/anais_texto_por_gt.php?idEncontro=MjQ=>. Acesso em: 15 de mar. de 2020.

LUKÁCS, Gabriella. Invisibility by Design: women and labor in Japan's digital economy. Durham: Duke University Press, 2020.

MARX, Karl. Grundrisse. São Paulo: Boitempo, 2011.

MARX, Karl; ENGELS, Friedrich. A Ideologia Alemã. São Paulo: Boitempo, 2007.

MATTOS, Maria Angela; BARROS, Ellen; OLIVEIRA, Max Emiliano. Metapesquisa em Comunicação: o interacional e seu capital teórico nos textos da Compós. E-compós, v.22, p. 1-21, 2019.

PEREIRA, Simone Luci e GHEIRART, Oziel. Coletivos de música eletrônica em São Paulo: usos da cidade, culturas juvenis e sentidos políticos. E-compós, v.21, n. 3, p. 3-21, 2018.

PEREIRA, Simone Luci; BORELLI, Silvia. Música "alternativa" na Vila Madalena: práticas musicais juvenis na cidade. Revista Fronteiras - Estudos Midiáticos (UNISINOS), v. 17, n. 3, p. 281-289, 2015.

PEREIRA, Simone Luci; PINTO, Teophilo. Na trilha dos compositores: músicas, redes, atores e mídias audiovisuais. Trabalho apresentado no GT Comunicação e Estudos de Som do XXV Encontro Anual da Compós. Goiânia: UFG, 2016. Disponível em: <http://www.compos.org.br/biblioteca/artigocompos2016_3387.pdf>. Acesso em: 09 de abr. de 2020.

PEREIRA, Vinícius Andrade. MERSBE: Mercado de ruídos e sons para o bem-estar: modulações da escuta e cultura aural contemporânea. Trabalho apresentado no GT Estudos de Som e Música do XXVII Encontro Anual da Compós. Belo Horizonte: PUCMG, 2018. Disponível em:

<http://www.compos.org.br/data/arquivos_2018/trabalhos_arquivo_IZX6N2C9JX 8Z087IJ7T1_27_6295_26_02_2018_12_31_12.pdf>. Acesso em: 11 de abr. de 2020.

Dossiê Crise, Feminismo e Comunicação - https://revistaecopos.eco.ufrj.br/

ISSN 2175-8689 - v. 23, n. 3, 2020

DOI: 10.29146/eco-pos.v23i3.27493 
QIU, Jack; GREGG, Melisa; CRAWFORD, Kate. Circuits of Labour: a labour theory of the iPhone era. TripleC, v. 12, n. 2, p. 564-581, 2014.

REIA, Jhessica. Ritmos da cidade: som, regulação e persistência da música de rua. Trabalho apresentado no GT Estudos de Som e Música do XXVII Encontro Anual da Compós. Belo Horizonte: PUC-MG, 2018. Disponível em:

<http://www.compos.org.br/data/arquivos_2018/trabalhos_arquivo_E5JCVH6XC BX088IED13W_27_6770_26_02_2018_14_49_45.pdf>. Acesso em: 09 de abr. de 2020.

RIZEK, Cibele. Viração e Trabalho: algumas reflexões sobre dados de pesquisa. Revista Estudos de Sociologia, v. 11, n. 21, p. 49-58, 2006.

SÁ, Simone P.; JANOTTI JR., Jeder (Orgs). Cenas Musicais. SP: Ed Estação das Letras, 2013.

SANDOVAL, Marisol. Enfrentando a Precariedade com Cooperação: cooperativas de trabalhadores no setor cultural. Parágrafo, v. 5, n. 1, p. 111-126, 2017.

SLACK, Jennifer Daryl. The Theory and Method of Articulation in Cultural Studies. In: MORLEY, David.; CHEN, Kuan-Hsing. (org.). Stuart Hall: critical dialogues in cultural studies. London: Routledge, 1996. p. 112-127.

SOARES, Thiago; PEREIRA, Simone Luci. Reguetón em Cuba: censura, ostentação e rasuras de políticas midiática. Trabalho apresentado no GT Estudos de Som e Música do XXVI Encontro Anual da Compós. São Paulo: Cásper Líbero, 2017. Disponível em:

<http://www.compos.org.br/data/arquivos_2017/trabalhos_arquivo_VKL3HT7N AE5QXFGEAJFY_26_5410_14_02_2017_10_51_34.pdf>. Acesso em: 09 de abr. de 2020.

VAN DOORN, Niels. Platform Labor: on the gendered and racialized exploitation of low-income service work in the 'on-demand' economy. Information, Communication \& Society, v. 20, n. 6, p. 898-914, 2017. 
VICENTE, Eduardo; KISCHINHEVSKY, Marcelo; DE MARCHI, Leonardo. A consolidação dos serviços de streaming: reconfiguração dos mercados de mídia sonora e desafios à diversidade musical no Brasil. Trabalho apresentado no GT Estudos de Som e Música do XXV Encontro Anual da Compós. Goiânia: UFG, 2016. Disponível em: <http://www.compos.org.br/biblioteca/streamingcompleto_3377.pdf>. Acesso em: 07 de abr. de 2020.

VIEIRA PINTO, Álvaro Vieira. O Conceito de Tecnologia. Rio de Janeiro: Contraponto, 2005.

WAJCMAN, Judy. Esclavos del tiempo: vidas aceleradas en la era del capitalismo digital. Barcelona: Paidos, 2017. 